\title{
EM TORNO DA CRÍTICA DE ENRIQUE DUSSEL À DEPENDÊNCIA EM RUY MAURO MARINI
}

\author{
Lucas Trindade Silva ${ }^{1}$
}

\begin{abstract}
Resumo: Num primeiro momento do artigo buscarei expor a crítica de Dussel à tradição dependentista, mais especificamente à obra de Ruy Mauro Marini que, segundo Dussel, inverteria a ordem lógica da problemática ao tomar a superexploração do trabalho e não a transferência de valor através do mecanismo da concorrência como fundamento da dependência. Num segundo momento farei um movimento de retorno à formulação da dependência em Marini, sobretudo no já clássico ensaio Dialéctica de la Dependencia e no seu Postscriptum. Trabalharemos a hipótese de que a crítica dusseliana a Marini não deve ser lida como uma superação da teoria da dependência em Marini, e aquilo que se define como uma crítica da inversão pode ser lida como uma diferença de ênfase no interior de um discurso compartilhado.
\end{abstract}

Palavras-chave: Dependência. Marini. Dussel. Dialética.

\begin{abstract}
At first the article seek to expose the Dussel's criticism to dependentist tradition, specifically the work of Ruy Mauro Marini who, according to Dussel, inverts the logical order of the problematic when he takes the superexploitation of labor and not the transfer of value through the mechanism of competition as the foundation of dependency. Secondly I will make a return movement to the formulation of dependency on Marini, especially now classic The Dialectics of Dependency and its Postscript. We will work the hypothesis that Dussel's criticism of Marini should not be read as an overcoming of dependency theory in Marini, and what is defined as criticism of the inversion can be read as a difference in emphasis within a shared speech.
\end{abstract}

Keywords: Dependency. Marini. Dussel. Dialectics.

\footnotetext{
${ }^{1}$ Doutorando em Sociologia pela Universidade de Brasília (UnB). Mestre em Sociologia pela Universidade Federal de Pernambuco (UFPE). Bacharel em Ciências Sociais pela Universidade Federal da Paraíba (UFPB). E-mail: trindadelucas88@gmail.com
} 
O propósito da presente reflexão é fazer um balanço da crítica dusseliana à tradição dependentista e do esforço do filósofo argentino de fundamentar rigorosamente - no interior do marco metodológico do projeto da crítica da economia política - as etapas argumentativas ou níveis de abstração que permitiriam a emergência de um discurso sobre a dependência. É o próprio Dussel quem elenca, no interior do debate latino-americano, a obra de Ruy Mauro Marini como a forma mais rigorosa, e mais próxima da dialética marxiana, de elaboração daquele discurso, embora acabe por tomar o secundário por primário, o fenomenal como fundamental, a forma como essência, centralizando a superexploração do trabalho (mecanismo de compensação da transferência de valor da periferia para o centro) como a legalidade específica da dependência. Formulando em termos precisos, em Marini, a violação da lei do valor no que diz respeito ao valor da força de trabalho aparece como normalidade, differentia specifica, nas chamadas situações de dependência estrutural. Para Dussel, a superexploração do trabalho de modo algum pode ser tomada como fundamento da dependência, deve sim ser compreendida como um dos possíveis mecanismos de compensação da transferência de valor, ou seja, como uma forma particular da dependência, e não como o seu conteúdo constitutivo.

Num primeiro momento do artigo, posterior a esta breve delimitação de propósitos, buscarei expor a crítica de Dussel $(1988,1990,2012)$ à tradição dependentista, mais especificamente à obra de Ruy Mauro Marini, e apresentar a afirmação que segue ao momento negativo: o conceito dusseliano de dependência que, tomando como ponto de partida o conceito de concorrência nos manuscritos marxianos, emerge através de uma analogia entre os níveis de competição intrassetorial, intersetorial e internacional no que se refere à transferência de valor entre capitais de distintas composições orgânicas; como um caminho que vai do mais ao menos abstrato, a saber, a concorrência no mercado mundial.

Num segundo momento farei um movimento de retorno à formulação da dependência em Marini, sobretudo no já clássico ensaio Dialéctica de la Dependencia e no seu Postscriptum - En Torno a Dialéctica de la Dependencia.

Embora Dussel explicite em sua crítica que o erro de Marini não está em ignorar a problemática da concorrência e da transferência de valor, na medida em que esta é tomada como ponto de partida de argumentação mariniana, mas sim em transformar a superexploração do 
trabalho em fundamento da dependência, não me parece que o clássico da filosofia da liberação faça justiça à profundidade com que Marini trata dos temas da concorrência, da transferência de valor, e da desigualdade na composição orgânica de capitais nacionais na conformação da dependência. É essa profundidade que tentarei expor no segundo momento da reflexão.

Diante do grau de consciência que a formulação mariniana da dependência apresenta em relação à problemática colocada por Enrique Dussel, ensaiarei a hipótese de que a centralização da superexploração do trabalho em Marini corresponde menos a um movimento de inversão, como nos apresenta Dussel, do que a uma concepção específica de movimento no sentido da produção, do método da crítica da economia política, orientado por um determinado contexto sócio-histórico. Minha hipótese é de que, para Marini, só a fundamentação da dependência no nível da produção e da exploração do trabalho, como superexploração do trabalho, significaria uma superação da fenomenalidade da circulação em que se concentrava a abordagem do intercâmbio desigual em sua versão cepalina. A identificação do movimento no sentido da produção à fundamentação da superexploração do trabalho como legalidade específica da dependência, por sua vez, parece orientada por um horizonte cognitivo marcado pelos contrastes radicais entre os países centrais (e suas experiências de Estado de bem-estar social) e o nível de pauperização das massas na periferia latino-americana (em sua maior parte assolada por regimes autoritários).

A importância precisa da crítica de Dussel está, assim, não na colocação da questão da concorrência e da transferência de valor entre capitais nacionais totais de composições orgânicas distintas como ponto de partida para a formulação de um discurso da dependência o que já está completamente presente na elaboração mariniana -, mas em salientar, também seguindo o método da crítica da economia política, que o movimento de teorização no sentido da produção ao fundamentar um conceito de dependência não precisa necessariamente tomar a superexploração do trabalho como legalidade específica. A lei, por assim dizer, é a própria transferência de valor, e esta se dá no sentido da produção por ancorar-se precisamente na desigualdade de composição orgânica entre capitais. Tem-se em Dussel um conceito marxista de dependência que não é teoricamente dependente do conceito de superexploração do trabalho. Este me parece ser o seu principal trunfo, pois permite pensar a dependência para além do horizonte histórico de sua emergência conceitual (os anos dourados do capitalismo central). Permite, portanto, pensar a dependência em tempos de crise generalizada do Welfare State e hegemonia neoliberal. 
Se assim for, a crítica dusseliana não aparece como uma superação da teoria da dependência em Marini, e aquilo que se define como uma crítica da inversão pode ser lida como uma diferença de ênfase no interior de um discurso compartilhado. Na nossa leitura, o esforço deve se orientar para uma cooperação das elaborações da dependência em Dussel e Marini.

\section{II}

Enrique Dussel (1988; 1990; 2012) se propõe preparar o terreno para uma elaboração rigorosa da categoria de dependência a partir de uma exegese dos manuscritos marxianos de 1857-1858 (conhecidos como Grundrisse) e de 1861-1863 (denominados Teorias da Maisvalia por Kautsky).

Na sua obra “A Produção Teórica de Marx: Um comentário aos Grundrisse”, Dussel (2012) reserva um capítulo, o décimo oitavo, exclusivamente à relação entre "Os Grundrisse e a "questão da dependência"'. Aqui Dussel considera como pressupostos de um projeto teórico de definição da dependência:

1) O esclarecimento das seis partes do projeto de Marx - o capital em geral, a renda da terra, o salário, o estado, as relações comerciais, o mercado mundial - como condição para uma abordagem conveniente de uma "sétima" parte - a questão da dependência;

2) Um discurso sobre a dependência só seria possível a partir de um discurso que supõe, mas não pode ser imediatamente derivado de um discurso sobre o capital em geral, "o que equivale a dizer que não se pode dar por suposta a análise do capital central nos estudos sobre o capital em geral". "[E]mbora Marx tenha tomado sempre, ou na maioria dos casos, a Inglaterra como exemplo do seu estudo do 'capital em geral', isto não significa que ao menos tenha começado o tratamento da Inglaterra como um país em que se encontra capital central'” (Dussel, 2012, p. $354)$.

Em suma, a questão de um capital, ramo de produção ou país "central" e "mais desenvolvido" em relação a outro capital, ramo de produção ou país "periférico" ou "menos desenvolvido" supõe o mercado mundial e é uma questão nova, que exige situar todo o discurso sob outra ótica (Ibid.: 354). 
Para Dussel, o erro dos dependentistas do final de 60 e dos anos 70 está nesta passagem "ao concreto diretamente, sem o prévio trânsito pelo abstrato (a nação como um todo abstrato)" (Ibid., p. 356). Embora acertem "ao indicar que somente a análise nacional (abstrata) é incompleta se não chega ao nível concreto do sistema mundial; e não só a dependência determina aspectos externos, mas sobredetermina determinações abstratas modificando-as internamente" (Ibid., p. 356).

Em Hacia un Marx Desconocido, Dussel (1988) mais uma vez dedica um capítulo exclusivo à relação entre os manuscritos marxianos de 1861-1863, sobre os quais se debruça durante toda a obra, e “o 'conceito' de dependência”. Novamente ele acusa os dependentistas de terem abruptamente passado do nível abstrato para o nível concreto, ou melhor, de terem prescindido da "lógica" para refletirem sobre a "história" (Dussel, 1988, p. 324). É este o equívoco identificado em autores como André Gunder Frank, assim como em Cardoso e Faletto, que escolhem o caminho da "demonstração histórica", ou seja, "a origem da diferença [entre países centrais e perifêricos, autônomos e dependentes] no tempo. Caminho fenomênico sem claridade essencial" (Ibid., p. 324).

Mesmo Ruy Mauro Marini, elogiado como o "trabalho que mais se aproxima da maneira como Marx tratava as questões" (Ibid., p. 326), "se equivoca na questão central, ao confundir um 'mecanismo de compensação' com uma determinação essencial” (Ibid., p. 327).

Eis o núcleo da crítica ao "excelente trabalho de Mauro Marini" (Ibid., p. 312) que, embora ponha "explicitamente o tema da 'transferência de mais-valia'... logo faz de uma compensação de tal transferência... a essência da dependência". Marini, a despeito de sua preocupação em "seguir a abordagem de autores preocupados com a 'troca desigual", e de “entender sobre 'transferência de mais-valia'... dado o uso correto de categorias como composição orgânica de capitais, diferenças em valores, preços de produção e preços de mercado, etc.”, erra, segundo Dussel (1990, p. 71), ao realizar uma inversão: toma a própria transferência de valor como secundária em relação ao mecanismo de compensação desta transferência de valor - a superexploração do trabalho como "fundamento" da dependência.

Para elaborar esta crítica Dussel se concentra enfática e repetidamente num conjunto de passagens da Dialéctica de la dependência (de 1973) que merece ser transcrita:

[...] América Latina debió hacerlo mediante una acumulación fundada en la superexplotación del trabajador. En esta contradicción radica la esencia de la 
dependencia latinoamericana. La tesis central [...] el fundamento de la dependencia es la superexplotación del trabajo (Marini apud Dussel, 1988, p. $327)$.

Dussel então se pergunta: "Como pode ser o fundamento (a essência) o que é a consequência ou a compensação da transferência de valor?” (Ibid., p. 313). Tal inversão, ou "confusão", continua Dussel, "se deve ao fato de não ter sido definido primeiramente e com claridade o "conceito"” de dependência.

É esta identificação de uma confusão conceitual mesmo nos esforços mais rigorosos de definição da dependência que permite ao autor argentino buscar uma refundação do conceito baseado nos manuscritos marxianos.

O "erro" que coloca sobre uma plataforma comum as diferentes definições da dependência está em tomar as "formas particulares" ou "fenômenos secundários" como nível fundamental de análise, obnubilando aquilo que é primário, a saber, a "dependência" como uma "relação social internacional e uma transferência de mais-valia entre capitais nacionais totais ou diferentes composições orgânicas no quadro da competição na ordem mundial" (Dussel, 1990, p. 63). É por esta razão que, para Dussel, o debate em torno da troca desigual, mais particularmente a formulação de Charles Bettelheim, ao indicar "que a diferença de composição orgânica... é o fenômeno fundamental, e que as diferenças salariais” (Ibid., p. 67) são daí derivadas, traz elementos mais produtivos para uma definição de dependência do que a forma de condução do debate na América Latina, onde questões lógicas e históricas foram permanentemente confundidas ${ }^{2}$.

Para Dussel (1988) o ponto de partida para o pôr da "questão da dependência" ou para a definição do "conceito de dependência" deve ser a categoria de concorrência, que é continuamente explorada na 'ordem investigativa' marxiana e ganha forma nomológica no Livro III d'O Capital: “La ley fundamental de la competencia capitalista [...] se basa [...] en esta diferencia entre valor y precio de costo de la mercancía y en la posibilidad, que surge de ello, de vender la mercancía con ganancia y por debajo de su valor” (Ibid., p. 334). Este ponto

\footnotetext{
${ }^{2}$ Segundo Dussel (1990) já Henryk Grossman concebia o problema da transferência de valor devido à tendência à equiparação das taxas de lucro, exemplificando empiricamente, no seu La ley de acumulación y el derrumbre del sistema capitalista, com a transferência de valor de Cuba para a América do Norte. Também Otto Bauer percebia as diferenças de composição orgânica como centrais para pensar a transferência de valor. Rosdolsky, por sua vez, no seu Gênese e Estrutura de O Capital de Marx, sintetiza o debate ao afirmar existir uma tendência à padronização da intensidade e produtividade do trabalho no interior das fronteiras nacionais, o que não acontece ao nível do mercado mundial.
} 
de partida deve ser rigorosamente desenvolvido, atentando para as analogias, na abordagem do capital do nível intrassetorial ao nível intersetorial, do nível intranacional ao nível internacional (Ibid., p. 335), sempre seguindo o método que vai do abstrato ao concreto. Assim, a "lei fundamental da dependência" deve ser formulada como a lei "da concorrência em geral no nível internacional" (Ibid., p. 345).

\begin{abstract}
Porque un 'capital global nacional' es dependiente en la competencia con respecto a otro más desarrollado, el país o nación que contiene o es determinado por dicho 'capital global' se denomina: 'nación' menos desarrollada, dependiente, etc., y no viceversa. (Ibid., p. 336). [...] La competencia, concluyendo, es el lugar real donde los diversos valores de las mercancías en una rama, o de las ramas, en un país, o de un país en el mercado mundial, llega a tener un precio. [...] La competencia es el 'lugar teórico de la dependencia' (Ibid., p. 339).
\end{abstract}

Deste modo, diferentes nações, enquanto formações sociais concretas, por terem diferentes graus de composição orgânica do capital, produzem mercadorias com valores distintos e, portanto, têm níveis salariais distintos. Este estado de coisas faz com que, no âmbito do mercado mundial, e da transformação dos valores em preços - onde se verifica uma tendência à padronização da taxa de lucro e de equalização dos preços, mas não da produtividade e intensidade do trabalho (como já percebido por Grossman, Bauer e Rosdolsky) -, os países centrais, com maior composição orgânica do capital, possam vender suas mercadorias por preços maiores (mesmo que concretamente sejam menores do que os preços das mercadorias produzidas por um capital com menor composição orgânica) em relação ao valor (tempo de trabalho objetivado) nelas cristalizado, criando a possibilidade de extração contínua de lucro extraordinário. Também por essa tendência à nivelação da taxa de lucro e dos preços no nível internacional, os capitais da periferia, a despeito de terem maior quantidade de tempo de trabalho objetivado (valor) em suas mercadorias, precisam diminuir os preços das mercadorias lançadas no mercado global, para assim terem condições de concorrência com os capitais centrais (Dussel, 1990, p. 74).

Chamo capital central desenvolvido àquele capital que, no nível da produção, integra relativamente maior capital constante $(\mathrm{Mp})$ que variável $(\mathrm{S})$, obtendo assim um produto com menor valor. Colocando este produto como mercadoria do capital periférico menos desenvolvido, ele pode aumentar seu preço, obtendo, deste modo, um lucro extraordinário (le). Chamo capital periférico menos desenvolvido àquele capital que, no nível da produção, integra menor 
capital constante (Mp') e, por isso, o produto inclui mais valor. Colocando este produto como mercadoria no mercado do capital central, para aí concorrer com o produto normal ou médio deve diminuir o seu preço e, portanto, mesmo realizando lucro $(l ')$, transfere mais-valia (tmv) (Dussel, 2012, p. 364).

Reitera-se assim, portanto, que, no nível da concorrência internacional - “o movimento que confronta dois capitais nacionais totais” (Dussel 1990, p. 85) - não há criação de valor, mas a distribuição do valor, a transferência de valor no sentido periferia $\rightarrow$ centro através da "equalização dos preços" (Ibid., p. 85).

Para além de uma imagem estanque da relação entre nações - como se a categoria da dependência só fosse válida no interior de um contexto histórico onde era possível pensar em processos de produção encerrados em fronteiras nacionais -, para Dussel (2012), o movimento de transnacionalização do capital, principalmente a partir da década de 1950, "significa um momento ampliado da 'questão da dependência' e não a sua negação" (Dussel, 2012, p. 367). Isto porque com a transnacionalização, os capitais de maior composição orgânica podem diminuir ainda mais os custos com capital variável, devido aos salários menores pagos na periferia do sistema capitalista mundial. A diferença entre a composição de valor desse capital e o seu preço será ainda maior do que a existente para o capital com alta composição orgânica que produz no interior das fronteiras dos países centrais, possibilitando para aquele "um superlucro maior que o obtido pelo próprio capital central (porque paga salários menores)" (Ibid., p. 367). Obviamente, uma das consequências principais das condições desiguais de concorrência postas pela desigualdade de composição orgânica dos capitais é o monopólio e correlatamente a destruição dos capitais mais fracos sem, no entanto, suprimir as condições periféricas que permitem tanto uma maior exploração do trabalho como a realização de lucros extraordinários ${ }^{3}$.

Explicitado este ponto de partida fundante da situação de dependência - a tendência à transferência de valor no confronto entre capitais de composições orgânicas desiguais - podese então indicar, seguindo o raciocínio dusseliano, diferentes formas de reprodução da dependência (Dussel, 2012, p. 89-90):

\footnotetext{
3 'It should be stated at the outset that 'monopoly' is nothing but the negative moment in the development of the concept of competition; that is, monopoly can be understood from within competition, from its essence, as a "possibility"' (Dussel, 1990, p. 73).
} 
1) Uma primeira é no sentido estrito e fundamental a própria 'lei' da dependência já anunciada - a transferência de valor no sentido periferia $\rightarrow$ centro causada pelas composições orgânicas desiguais dos capitais nacionais totais confrontados, através de suas mercadorias, no mercado mundial;

2) num segundo, no caso de uma mercadoria produzida exclusivamente por capital periférico (café, exemplifica Dussel), pode haver anulação da concorrência pelo capital mais desenvolvido do país central (sem anular "a lei da transferência de mais-valia nem a lei do valor"), organiza-se assim, articulando instrumentos econômicos, políticos e militares, um "monopólio do comprador";

3) Outro mecanismo é a imposição de um "preço de monopólio" por parte do capital mais desenvolvido produtor exclusivo de determinada mercadoria (por exemplo, bens de capital), neste caso o "comprador (o capital do país periférico) paga mais trabalho objetivado por menos (transfere mais-valia quando compra os meios de produção necessários)";

4) Um quarto mecanismo é o investimento financeiro (em carteira) em países periféricos, onde a transferência de valor dá-se através de juros e outros retornos financeiros canalizados para o estrangeiro;

5) Um quinto mecanismo é justamente através da chamada "corporação transnacional", que transfere mais-valia por ter na periferia, como vimos, condições ainda mais vantajosas de reduzir o valor da massa de mercadorias produzidas.

A superexploração do trabalho, embora opere também no âmbito das corporações transnacionais que se aproveitam dos baixos salários em países dependentes para atingir superlucros, aparece como mecanismo de compensação de extrema importância, sobretudo para os capitais nacionais periféricos, profundamente dependentes da importação de bens de capital e de capital-dinheiro do exterior para viabilizar e financiar a produção. Isto de modo algum é negado por Dussel que, na sua Tese 8 sobre a dependência escreve:

Chamamos Cce [capital central] àquele capital que primeiro, e de modo permanente, desloca a obtenção de mais-valia da mais-valia absoluta para a mais-valia relativa. Chamamos Cpe [capital periférico] àquele capital que prolonga a obtenção de mais-valia absoluta, não só estendendo as horas de trabalho ou aumentando a população trabalhadora, mas a intensidade do 
trabalho (superexploração absoluta) que, de qualquer maneira, produz um maior valor no produto-mercadoria (o que, na circulação, significará preço maior) (Dussel, 2012, p. 362).

O interesse de Dussel ao criticar a dependência em Marini não é negar a existência da superexploração da força de trabalho ${ }^{4}$ em países dependentes. Trata-se para o autor argentino de "um aspecto igualmente essencial da diferença entre o capital central e o capital periférico. Mas, observe-se, não é a única determinação que funda a diferença e nem mesmo a mais importante" (Ibid., p. 362). Aqui mais uma vez se evidencia que o problema de Dussel com a dependência em Marini está em transformar a superexploração do trabalho em determinante último, lei, da situação de dependência. Marini transforma um fenômeno da dependência em seu fundamento. Opera uma inversão.

É precisamente esse julgamento crítico que nos leva à escrita. É justo caracterizar o esforço mariniano como uma confusão nos termos de definição do conceito de dependência? A compreensão da superexploração do trabalho como "fundamento" da dependência indica uma inversão, um equívoco? Embora consciente e rigoroso no tratamento das categorias de concorrência, transferência de valor, composição orgânica do capital, etc., o que leva Marini a centralizar a superexploração do trabalho como legalidade específica da dependência?

\section{III}

Como vimos, Dussel dá prova da sua honestidade intelectual ao reconhecer o mérito e o rigor das contribuições marinianas para o debate da dependência. Desde o princípio da sua crítica deixa bastante claro que Marini apresenta "explicitamente o tema da 'transferência de mais-valia", embora no continuum argumentativo faça "de uma compensação de tal transferência... a essência da dependência” (Dussel, 1988, p. 312). Para nós, não se trata apenas de uma consciência teórica, da parte de Marini, em relação aos debates sobre troca desigual, o método da crítica da economia política, e o rigor no trato com as categorias aí postas, mas de desenvolver plenamente essas categorias, e de centralizar o conceito de superexploração do

\footnotetext{
4 "La sobreexplotación expuesta por Mauro Marini puede explicarse perfectamente como compensación de la transferencia de plusvalor. Al aumentar la transferencia anualmente, e intentando el capital periférico obtener una misma tasa de ganancia, el producto debe mantener su valor, aumentar su plusvalor, y disminuir relativamente el valor del salario en él objetivado. La sobreexplotación es la contrapartida de la sobretransferencia" (Dussel, 1988, p. 355).
} 
trabalho não por causa de uma confusão lógica, mas devido à determinação última da prática teórica pela prática social, ou seja, pelo contexto sócio-histórico no qual a elaboração mariniana da teoria da dependência estava inserido. Vejamos.

Para principiar a discussão, tomemos o ensaio de 1966 intitulado "La dialéctica del desarrollo capitalista en Brasil", onde o conceito de superexploração da força de trabalho ainda não está definido, mas onde a necessidade da sua definição para um aprofundamento do conceito de subimperialismo já se evidencia, como uma opacidade que estava prestes a vir a luz.

La expansión imperialista de la burguesía brasileña tiene que basarse en una mayor explotación de las masas trabajadoras nacionales, sea porque necesita de una producción competitiva para el mercado externo, lo que implica salarios bajos y mano de obra disponible, es decir, un elevado índice de desempleo, sea porque se procesa juntamente con un aumento de la penetración de los capitales norteamericanos, lo que exige la extracción de un sobrelucro de la clase obrera. Esa intensificación de la explotación capitalista del pueblo brasileño es factor suficiente para intensificar la lucha de clases, algo que pone en riesgo la oposición de la burguesía (Marini, 2008, p. 79).

Como está explícito, a superexploração do trabalho na situação de dependência, aqui pensada como "una mayor explotación de las masas trabajadoras nacionales", nos é introduzida como um fenômeno que emerge da necessidade dos capitais nacionais periféricos em fazer frente à competição com os capitais centrais, seja ao lançar suas mercadorias no mercado externo, seja para ter condições de concorrer com a produção das corporações transnacionais no interior do próprio território nacional. Uma maior exploração das massas trabalhadoras nacionais é necessária tendo em vista contrarrestar a tendência dos monopólios à destruição dos capitais menos desenvolvidos ou à drástica redução da margem de lucro destes.

Aí, em 1966, ainda não temos um trato minucioso das categorias de concorrência, transferência de valor, diferenças de composição orgânica, valor, preço de produção e preço de mercado, mas já há claramente a delimitação do marco geral que levará à definição rigorosa do conceito de dependência: aponta-se para a relação necessária entre as tendências da concorrência intercapitalista (momento da circulação) e as formas de contrarrestar essas tendências no interior das economias periféricas (momento da produção).

A "Dialéctica de la dependencia", de 1973, representa um imenso salto na elaboração teórica mariniana e no rigor na definição do conceito de dependência. Como Dussel - em suas 
exegeses dos manuscritos marxianos e o pôr do conceito de dependência em seu locus de abstração adequado -, desde o princípio Marini está preocupado com questões metodológicas. Assim como em Dussel, esta preocupação metodológica de princípio visa limpar o terreno do debate sobre a dependência latino-americana, onde era perceptível, ora "a substituição do fato concreto pelo conceito abstrato [história econômica]", ora "a adulteração do conceito [de dependência] em nome de uma realidade rebelde a aceitá-lo em sua formulação pura [sociologia]" (Marini, 2008, p. 107-8). Doze anos antes do primeiro trabalho de exegese dos manuscritos marxianos por Dussel - La producción teórica de Marx: Un comentario a los Grundrisse, de 1985 -, Marini já se opunha a uma mera transposição das categorias e conceitos da crítica da economia política para pensar a realidade latino-americana. Para o pensador de Barbacena, "as categorias marxistas devem ser aplicadas, portanto, à realidade como instrumentos de análise". Não se trata de inserir a realidade no texto da crítica da economia política em sua formulação genética. A exigência para uma dialética da dependência é a fidelidade ao "rigor conceitual e metodológico" do materialismo dialético (Ibid., p. 109-10). A proximidade com a ideia dusseliana da dependência como um "discurso novo" na esteira do projeto da crítica da economia política é imediatamente evidente.

Embora Marini (2008) não inicie, tal qual Dussel, a sua discussão a partir do projeto da crítica da economia política de $1857^{5}$, a própria estrutura do texto da Dialéctica de la dependencia explicita a consciência de Marini sobre o nível de abstração e de desenvolvimento das categorias da crítica da economia política do qual o discurso sobre a dependência deve partir. Logo após a necessária digressão metodológica, Marini subdivide o ensaio em: “1. La integración al mercado mundial"; "2. El secreto del intercambio desigual"; "3. La

\footnotetext{
5 "O plano de 1857 previa que a obra seria dividida da seguinte maneira: LIVRO I. SOBRE O CAPITAL

a) $O$ capital em geral

1) Processo de produção do capital

2) Processo de circulação do capital

3) Lucro e juros

b) Seção sobre a concorrência

c) Seção sobre o sistema de crédito

d) Seção sobre o capital dividido em ações

LIVRO II. SOBRE A PROPRIEDADE DA TERRA

LIVRO III. SOBRE O TRABALHO ASSALARIADO

LIVRO IV. SOBRE O ESTADO

LIVRO V. SOBRE O COMÉRCIO EXTERIOR

LIVRO VI. SOBRE O MERCADO MUNDIAL E AS CRISES” (Rosdolsky, 2001, p. 28-9).
} 
superexplotación del trabajo"; “4. El ciclo del capital en la economía dependiente”; “5. El proceso de industrialización"; "6. El nuevo anillo de la espiral”.

Vê-se já na estruturação o cuidado em estabelecer um movimento de descenso do abstrato ao concreto, começando pela explicitação das funções históricas dos países latinoamericanos no interior do mercado mundial e uma definição geral de dependência em contraste com a cronologicamente anterior situação colonial (contraste embaçado na elaboração da dependência em André Gunder Frank); passando pelas relações de intercâmbio desigual, onde se trata explicitamente do problema da concorrência e da transferência de valores; para só assim poder tratar da forma de articulação da produção no interior da economia dependente, desde o processo de substituição de importações até a intensificação do processo de trasnacionalização na etapa do capitalismo monopolista. Nesse continuum rigoroso de argumentação, inúmeras correlações são ensaiadas. De fundamental importância é a relação entre reprodução da dependência e reprodução de um mercado interno atrofiado, característica intrínseca à industrialização tardia e ao chamado ciclo do capital na economia dependente, pelo menos em seu diagnóstico na década de 1970.

Para Marini, a dependência é “entendida como uma relação de subordinação entre nações formalmente independentes, em cujo marco as relações de produção das nações subordinadas são modificadas ou recriadas para assegurar a reprodução ampliada da dependência" (Ibid., p. 111). Vê-se que essa definição geral de modo algum entra em contradição com a "definição essencial, em geral" de dependência em Dussel, como "relação de concorrência entre os capitais central e periférico, situando-a tanto no nível da produção (momento essencial) quanto no da circulação ou da troca (momento superficial ou fenomênico)" (Dussel, 2012, p. 363). A princípio, ambos parecem convergir para uma definição sobredeterminada (na circulação e na produção) da reprodução da dependência, preservando o "momento preponderante" produtivo. Mas continuemos a acompanhar a ordem expositiva da Dialéctica de la dependencia.

Ainda na seção sobre "La integración al mercado mundial", Marini (2008, p. 113-5) elenca algumas das principais funções da América Latina na circulação global de mercadorias: 1) o fornecimento de "meios de subsistência de origem agropecuária", elemento crucial para o diferenciação da divisão do trabalho, especialização manufatureira, e ampliação da população urbana e da classe trabalhadora em alguns países europeus; 2) a "formação de um mercado de matérias primas industriais, cuja importância cresce em função do próprio desenvolvimento 
industrial"; 3) um grau elevado de exploração do trabalhador que permite aos países centrais deslocarem seu eixo de acumulação da mais-valia absoluta para a mais-valia relativa, esta dependente sobretudo do "aumento da capacidade produtiva do trabalho que simplesmente da exploração do trabalhador".

Está aí, ao apontar a terceira função que a América Latina exerceu no desenvolvimento do capitalismo central, a primeira enunciação do problema da "superexploração do trabalho": a dicotomia entre desenvolvimento da mais-valia relativa como forma predominante de exploração no centro e da superexploração do trabalho como predominância na periferia. É precisamente para explicar esta dicotomia que Marini se debruçará, na ordem expositiva, sobre o tema do intercâmbio desigual e seu segredo na segunda seção da Dialéctica de la dependencia. É também aqui que Marini desenvolverá com plena maturidade as categorias enfatizadas por Dussel na década de 80.

Antes de qualquer coisa, a preocupação de Marini (Ibid., p. 115-7) é em definir rigorosamente o conceito de mais-valia relativa distinguindo-o do conceito de produtividade, pois, se esta é "condição por excelência da mais-valia relativa, uma maior capacidade produtiva do trabalho não assegura por si mesma um aumento da mais-valia relativa”. O aumento da produtividade permite a um capitalista a produção de mais mercadorias em um mesmo período de tempo em que eram produzidas menos mercadorias com uma menor produtividade, o que não cria mais valor, mas permite reduzir o valor individual da mercadoria "em relação ao valor que as condições gerais de produção [tempo de trabalho socialmente necessário] a atribui, obtendo assim uma mais-valia superior à dos seus competidores - ou seja, uma mais-valia extraordinária". Para que o aumento da produtividade venha necessariamente acompanhado de um aumento do grau de exploração da força de trabalho, ou seja, aumento do trabalho excedente com diminuição do trabalho necessário numa dada jornada de trabalho, deve haver uma diminuição do "valor social" daquelas mercadorias "necessárias à reprodução da força de trabalho", os "bens-salário". Há, portanto, uma correlação geral entre desenvolvimento da maisvalia relativa e desvalorização dos bens-salário provocada pela especialização agro-primária das economias latino-americanas.

Esta correlação é estabelecida por Marini (Ibid., p. 117) ao refletir sobre as funções da América Latina no mercado mundial. Dada a sua especialização no fornecimento de produtos primários, constata-se uma tendência à depreciação desses produtos a nível global, o que então permitirá "reduzir o valor real da força de trabalho nos países industriais" e que o "incremento 
da produtividade se traduza ali em taxas da mais-valia cada vez mais elevadas". Como sabemos, a crescente generalização da mais-valia relativa como forma predominante de exploração da força de trabalho tende a se traduzir em diminuição da taxa de lucro, visto que a "composiçãovalor do capital”, na expressão utilizada por Marini, aumenta em detrimento da composiçãotrabalho, o trabalho morto predomina sobre o trabalho vivo.

Esclarecidos os mecanismos que conferiram aos países latino-americanos - por sua especialização no fornecimento de bens-salário e pela depreciação do valor desses bens provocada precisamente por esta especialização - uma função central na tradução do aumento da produtividade em predominância da exploração relativa da mais-valia no interior dos países industriais, e tendo em vista a tendência de incremento da composição orgânica do capital em detrimento do trabalho vivo colocada pela generalização da mais-valia relativa, Marini tem o terreno preparado para uma abordagem da "questão do intercâmbio desigual" que não a reduza aos mecanismos de oferta e procura, nem a impute unicamente às pressões diplomáticas e militares dos países mais poderosos ${ }^{6}$.

É aqui onde Marini desenvolverá plenamente as categorias enfatizadas por Dussel, doze anos depois, em sua definição de dependência.

Teóricamente, el intercambio de mercancías expresa el cambio de equivalentes, cuyo valor se determina por la cantidad de trabajo socialmente necesario que incorporan las mercancías. En la práctica se observan diferentes mecanismos que permiten realizar transferencias de valor, pasando por encima de las leyes del intercambio, y que se expresan en la manera como se fijan los precios de mercado y los precios de producción de las mercancías (Ibid., p. 121, itálico meu).

O caráter transgressor das transferências de valor - baseadas nas contradições surgidas na relação entre os "preços de mercado" e os "preços de produção" de mercadorias determinadas - tende a aprofundar-se ao passar do nível intrassetorial ao intersetorial e então internacional. "É assim que, por efeito de uma maior produtividade do trabalho, uma nação pode apresentar preços de produção inferiores aos seus concorrentes, sem por isto baixar significativamente os preços de mercado que as condições de produção contribuem para fixar"

\footnotetext{
6 "No es porque se cometieron abusos contra las naciones no industriales que éstas se han vuelto económicamente débiles; es porque era débiles que se abusó de ellas. No es tampoco porque produjeron más de lo debido que su posición comercial se deterioró, sino que el deterioro comercial fue lo que las forzó a producir en mayor escala" (Marini, 2008, p. 120).
} 
(Marini, 2008, p. 121). Essa diferença será apropriada como "lucro extraordinário" pela nação com maior produtividade, de forma "similar" à apropriação "do fruto da produtividade do trabalho" pelos "capitais individuais".

Tais tendências tendem a ocorrer onde quer que estejam desenvolvidas "relações capitalistas de produção", e de forma ainda mais incisiva quando se trata de nações industrializadas, o que já aponta para o aprofundamento da dependência no correr dos processos de industrialização periféricos. No caso de troca entre uma nação produtora de manufaturas e outra de bens primários, a tendência é de "dupla" transferência de valor, articulando os mecanismos de transferência típicos da concorrência a um decisivo movimento de falseamento da lei do valor proporcionado pelas condições de monopólio, ampliando a margem de diferença ente o custo de produção e o preço de mercado.

Frente à transferência de valor, a nação desfavorecida lança mão de "um mecanismo de compensação" (Ibid., p. 122), incrementando "a massa de valor produzida" através de "uma maior exploração do trabalho", intensificando-a, prolongando-a, e mesmo “combinando os dois procedimentos" (Ibid., p. 123) ${ }^{7}$.

Lo que aparece claramente, pues, es que la naciones desfavorecidas por el intercambio desigual no buscan tanto corregir el desequilibrio entre los precios y el valor de sus mercancías exportadas (lo que implicaría un esfuerzo redoblado para aumentar la capacidad productiva del trabajo), sino más bien compensar la pérdida de ingresos generados por el comercio internacional, recurriendo a una mayor explotación del trabajador (Ibid., p. 123).

Aparece como produção típica da situação da dependência uma baixa "composiçãovalor do capital" (em relação a outras nações industriais desenvolvidas), contrarrestada pelo aumento do "grau de exploração do trabalho" como meio de elevação das "taxas de mais-valia e de lucro" (Ibid., p. 126). "Chamada a contribuir para a acumulação de capital com base na produtividade do trabalho nos países centrais, a América Latina o faz através de uma acumulação baseada na superexploração do trabalhador. Nessa contradição reside a essência da

\footnotetext{
${ }^{7}$ Jaime Osorio (2009, p. 113-4) nos oferece uma formalização bastante precisa do conceito de superexploração do trabalho: "La superexplotación del trabajo puede adoptar tres formas básicas: en primer lugar, mediante la compra de la fuerza de trabajo por un salario inferior a su valor, es decir, pagando por ella menos de lo necesario para que se reproduzca en condiciones normales. [...] Una segunda forma en la que el capital puede violar el valor de la fuerza de trabajo se base en la prolongación anormal de la jornada laboral. [...] La última forma de la superexplotación se basea en la intensificación del trabajo".
} 
dependência latino-americana" (Ibid., p. 132). Em sua gênese e desenvolvimento orientada para o mercado mundial, e com uma classe trabalhadora superexplorada marginal a um padrão aceitável de consumo, a produção das economias latino-americanas terá como formas de realização principais um mercado interno restrito e a circulação global, evidenciado, em seu ciclo do capital característico, a cisão entre a produção e a circulação (interna) de mercadorias.

No movimento de pensamento que parte da análise da integração histórica e funcional latino-americana ao mercado mundial, chega à legalidade específica da produção capitalista na situação de dependência e daí elabora o esquema reprodutivo do ciclo do capital na economia dependente, Marini (2008, p. 131) decididamente segue um método que vai "da circulação à produção, da vinculação ao mercado mundial ao impacto que isto acarreta sobre a organização interno do trabalho, para então voltar a repensar o problema da circulação". Decompõe-se analiticamente uma representação geral da totalidade, a elaboração das suas determinações reflexivas é explicitada, e então retorna-se ao todo enriquecido de conceitos capazes de torná-lo inteligível e logicamente coerente. Neste movimento metodológico, a

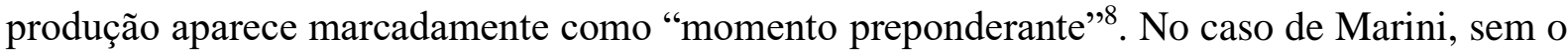
conceito de superexploração do trabalho é impossível a compreensão do conceito de ciclo do capital na economia dependente, ambos desde o princípio definidos pela articulação da economia dependente no mercado mundial e os mecanismos internos gerados pela transferência internacional de valores.

Exposta simplificadamente a coerência e o rigor da elaboração mariniana da teoria da dependência, vemos que nesta a problemática articulada da transferência de valor, da desigualdade de composições orgânicas de capitais, das contradições entre preço de produção e preço de mercado, não aparece apenas como um mero ponto de partida. Tais categorias são plenamente elaboradas pela pena mariniana ${ }^{9}$ antes de chegar ao conceito de superexploração

\footnotetext{
8 “O importante aqui é apenas destacar que, se produção e consumo são considerados como atividades de um sujeito ou de muitos indivíduos, ambos aparecem em todo caso como momentos de um processo no qual a produção é o ponto de partida efetivo, e, por isso, também o momento predominante [übergreifende Moment]. O próprio consumo, como carência vital, como necessidade, é um momento interno da atividade produtiva. Mas esta última é o ponto de partida da realização e, por essa razão, também seu momento predominante, o ato em que todo o processo transcorre novamente. O indivíduo produz um objeto e retorna a si ao consumi-lo, mas como indivíduo produtivo e que se autorreproduz. O consumo aparece, assim, como momento da produção" (Marx, 2011, p. 49). 9 Em seu En torno a dialéctica de la dependencia (postscriptum), também de 1973, Marini (2008, p. 155) exprime de forma concisa o seu domínio da problemática da transferência de valor: "La diversidad del grado de las fuerzas productivas en las economías que se integran al mercado mundial conlleva diferencias significativas en sus respectivas composiciones orgánicas de capital, que apuntan a distintas formas y grados de explotación del trabajo. A medida que se va estabilizando el intercambio entre ellas, tiende a cristalizarse un precio comercial cuyo término de referencia es, más allá de sus variaciones cíclicas, el valor de las mercancías producidas. En consecuencia, el grado de participación en el valor global realizado en la circulación internacional es mayor para las economías de
} 
do trabalho como fundamento, essência ou legalidade da economia dependente. Diante deste desenvolvimento pleno das categorias, não nos parece correto conceber a teoria mariniana da dependência como uma inversão lógica (de uma hierarquia real) que toma o fenômeno (a superexploração do trabalho como mecanismo de compensação) como essência (transferência de valor fundada nas desigualdades de composição orgânica dos capitais centrais e periféricos). A ênfase na superexploração do trabalho no modelo mariniano não opera uma distorção da realidade da dependência como o faria uma inversão. Tal ênfase, por sua vez, pode ser explicada, num nível puramente hipotético, por dois principais fatores, um teórico e outro histórico:

1) Se aceitarmos a ideia lançada por Osorio (2004, p. 138) de que a Dialéctica de la dependencia de Marini é um esforço de formular as “bases da economia política da dependência”, nos parece plenamente plausível pensar que, para este esforço, chegar ao fundamento da dependência, enquanto capitalismo sui generis, necessariamente implicava em chegar - assim como para a crítica da economia política a mais-valia aparece como o fundamento da acumulação de capital em geral - a uma forma também sui generis de exploração do trabalho ${ }^{10}$;

2) Para além de razões exclusivamente teóricas, o contexto sócio-histórico de formulação da teoria mariniana da dependência parece ter uma influência decisiva para a ênfase dada por Marini ao conceito de superexploração do trabalho. Vejamos.

No começo da década de 70, de um lado, sobretudo ao Norte, países como Alemanha, Inglaterra, França, Estados Unidos, entre outros, sinalizavam fortes indicadores de bem-estar social, proporcionados por diversos fatores, entre eles: elevada produtividade (incremento

composición orgánica más baja, o sea, para la economía dependiente. En términos estrictamente económicos, las economías industriales se enfrentan a esa situación recurriendo a mecanismos que tienen como resultado extremar las diferencias iniciales en que se daba el intercambio. Es así como echan mano del aumento de su productividad, con el fin de rebajar el valor individual de las mercancías en relación con el valor medio en vigor y de elevar por lo tanto su participación en el monto total de valor intercambiado; esto se verifica tanto entre productores individuales de una misma nación como entre las naciones competidoras".

10 "La tarea fundamental de la teoría marxista de la dependencia consiste en determinar la legalidad específica por la que se rige la economía dependiente. Ello supone, desde luego, plantear su estudio en el contexto más amplio de las leyes de desarrollo del sistema en su conjunto y definir los grados intermedios mediante los cuales esas leyes se van especificando. Es así como la simultaneidad de la dependencia y del desarrollo podrá ser realmente entendida. El concepto de subimperialismo emerge de la definición de esos grados intermedios y apunta a la especificación de cómo incide en la economía dependiente la ley según la cual el aumento de la productividad del trabajo (y por ende de la composición orgánica del capital) acarrea un aumento de la superexplotación. [...] el fundamento de la dependencia es la superexplotación del trabajo" (Marini, 2008, p. 162-3). 
constante da composição orgânica); forte organização sindical e partidária dos trabalhadores, o que se traduzia em amplo poder de barganha e participação nos lucros; sobreacumulação de capital devido à apropriação de valores transferidos dos países dependentes; generalização do padrão fordista de consumo; ampliação da rede de serviços públicos componentes do salário indireto, etc.

Do outro lado, sobretudo ao Sul, a intensificação do processo de industrialização através da internacionalização do mercado interno de países como o Brasil, conduzido por um regime político opressor que mantinha atrofiadas as organizações trabalhistas, não trouxe, como escreve Theotônio dos Santos (1998, p. 104), “autonomia de decisão, por que a industrialização passava a ser comandada pelo investimento externo, baseado na empresa multinacional, cujo centro de poder continuava nos polos centrais da economia mundial". Também não trouxe “distribuição de renda, por que se fazia na época do capitalismo oligopólico e financeiro que tende a concentrar em grandes grupos econômicos o poder e a riqueza". Soma-se a isso que "a tecnologia moderna [incorporada] valorizava o trabalho qualificado e as atividades gerenciais em detrimento dos assalariados, provocando uma forte diferenciação de renda no interior dos assalariados", além de ser uma tecnologia "poupadora" de força de trabalho (capital variável), incapaz de "incorporar a mão de obra liberada do campo e das atividades de autoconsumo".

É este estado de coisas que a elaboração do ciclo do capital na economia dependente busca explicar de forma sintética. O ciclo do capital na economia dependente começa em D-M - dependente das inversões diretas (poupadora de mão de obra) e indiretas do capital estrangeiro - entra em P - marcado pela superexploração do trabalho como mecanismo de compensação e a predominância do setor produtivo de bens suntuários - e termina em M'-D' - realização do valor no mercado interno restrito ou mesmo fora do mercado nacional. Tal ciclo de dependência e concentração é o que explica, no final da década de 70, quando Marini escreve o ensaio El Ciclo del Capital en la Economía Dependiente, que nas economias dependentes, "no melhor dos casos, apenas $20 \%$ da população [tivesse] níveis de consumo aceitáveis ou mais aceitáveis, enquanto que $80 \%$ [vivia] em condições de baixo consumo" (Marini, 1979, p. 12).

O contraste radical entre os anos dourados do capitalismo central e a extrema pauperização vivida na periferia latino-americana nos aparece, portanto, como elemento decisivo para entender a centralização da superexploração do trabalho (geradora de subconsumo no nível da realização) como legalidade específica na elaboração mariniana da dependência. 


\section{IV}

A nossa inquietação não é se a superexploração do trabalho nunca foi ou deixou de ser um mecanismo fundamental na reprodução da dependência, mas, na esteira de Dussel, de refletir sobre as consequências de pensá-la como legalidade específica da dependência, ou seja, como uma forma de acumulação típica da economia dependente em decisivo contraste com os centros de acumulação do capital.

Se a resposta for sim, se afirmarmos que ela continua sendo a legalidade específica da dependência, o risco é manter um reforço do contraste que impeça de perceber a vigência de formas de superexploração do trabalho no contexto dos países centrais, seja como extração da mais-valia nas mais diversas formas de assalariamento (da produção propriamente aos serviços), seja através da chamada por Lapavitsas (apud Amaral, 2013) de "'financeirização dos rendimentos do trabalho"” - "espécie de expropriação financeira dos salários" através da qual "parte das rendas do trabalho é direcionada aos bancos e às instituições financeiras de um modo geral, tanto na forma de juros, quanto pelo pagamento de taxas e comissões referentes à prestação de serviços financeiros” (Amaral, 2013, p. 13). Espoliação esta - fundada na ampliação de "empréstimos tomados para o pagamento de hipotecas, gastos com educação, saúde, bens de consumo, etc., assim como com a aquisição de ativos financeiros tais como fundos de pensão, seguros, dentre outros" (Ibid., p. 111) - que, como a crise de 2008 evidenciou, incide sobre a massa de trabalhadores tanto dos centros como das periferias do sistema capitalista mundial.

Obviamente, alguém pode imediatamente atrelar a vigência de formas de superexploração no centro do capitalismo a períodos de crise do capitalismo, enquanto na periferia a superexploração é normalidade. Mas se tomarmos como referência a atual crise econômica mundial, a recuperação de um padrão de reprodução do capital análogo aos anos dourados do Welfare State nos países centrais ainda não aparece no horizonte, e não parece cauteloso tomar a recuperação de um tal padrão de reprodução do capital como algo inerente às recuperações de crise ou fases cíclicas de ascensão econômica.

Se a reposta for não, aceitaremos - como Marini (2008) explicitamente colocou em ensaio tardio, de 1997, onde buscava definir as principais tendências da chamada globalização 
capitalista - a possibilidade de uma generalização da superexploração da força de trabalho a nível global provocada pela intensificação do incremento da composição orgânica do capital e pela maior exploração da força de trabalho como contratendência a queda da taxa de lucro que aquele incremento motiva, aliada ao fenômeno do desemprego estrutural, da financeirização, e da terceirização e flexibilização do trabalho.

Deriva daí o fim de relações hierárquicas entre nações e, portanto o fim da dependência? É o próprio Marini no mesmo texto de 1997 que nos oferece elementos para uma resposta negativa.

Segundo Marini, apoiado na obra de R. B Reich, The Work of Nations, a transnacionalização apresenta como características fundamentais: 1) uma difusão sem precedentes da indústria, abrindo "amplo campo para o deslocamento da produção manufatureira aos países que apresentam taxas salariais inferiores", causa fundamental para a diminuição da "oferta de trabalho" num país como os EUA; 2) o esforço dos países centrais (no argumento o modelo é os EUA) de ampliação do trabalho qualificado, com alto nível educacional, "do nível pré-escolar ao superior, a fim de compensar [aquela] redução da oferta interna de emprego" (Marini, 2008: 258). Tais características são centrais para a conformação de uma nova divisão internacional, operante "no plano da própria força de trabalho e não, como antes, através da posição ocupada no mercado mundial pela economia nacional na qual o trabalhador" se insere. Trata-se, nesta nova etapa, "da participação do trabalhador em um verdadeiro exército industrial globalizado em processo de constituição, em função do grau de educação, cultura e qualificação produtiva de cada um” (Ibid., p. 259).

Não se trata de uma periferização do globo, Marini de forma muito perspicaz percebe a manutenção da dialética da dependência nesta nova configuração da divisão internacional do trabalho.

Un análisis más detallado nos muestra, empero, que los países desarrollados conservan dos triunfos en la mano. El primero es su inmensa superioridad en materia de investigación y desarrollo, que es lo que hace posible la innovación técnica; existe allí un verdadero monopolio tecnológico que agrava la condición dependiente de los demás países. El segundo es el control que ejercen en la transferencia de actividades industriales a los países más atrasados, tanto por su capacidad tecnológica como de inversión, control que actúa de dos maneras: una, transfiriendo prioritariamente a los países más atrasados industrias menos intensivas en conocimiento; dos, dispersando entre diferentes naciones las etapas de la producción de mercancías; de esa manera impiden el surgimiento de economías nacionalmente integradas (Ibid., p. 259). 
Vemos assim que, diante da tendência à generalização da superexploração do trabalho promovida pelo aprofundamento da globalização neoliberal e da reestruturação produtiva, Marini verá, do ponto de vista da crítica da economia política, a desigualdade entre as nações repousando primordialmente na desigualdade de distribuição da tecnologia e, portanto, a dependência como a reprodução de uma situação estrutural de atraso tecnológico em relação aos países centrais desenvolvidos. A ênfase, convergindo com a elaboração dusseliana, se transfere da superexploração do trabalho como legalidade específica para as diferenças em termos de desenvolvimento técnico e tecnológico, podemos dizer, para os desníveis nacionais de desenvolvimento da composição orgânica ou "composição-valor” do capital.

Conclui-se assim, de forma puramente sugestiva, que um conceito de dependência sensível à superexploração do trabalho (mas que não a tome como sua determinação última), atentando principalmente para a reprodução e transformação das desigualdades de composições orgânicas em termos de capitais centrais e periféricos, é um conceito mais flexível e mais capaz: na apreensão da diversidade de formas de hierarquização das nações no sistema capitalista mundial contemporâneo; e para lidar com as mudanças no padrão de reprodução do capital seja no centro seja na periferia.

\section{Referências}

AMARAL, Marisa Silva (2013). Breves considerações acerca das teorias do imperialismo e da dependência ante a financeirização do capitalismo contemporâneo. In: Revista Pensata, v. 3 , n. 1 , novembro.

DUSSEL, Enrique (1988). Hacia un Marx Desconocido. Un Comentario de los Manuscritos del 61-63. México: Siglo XXI.

(1990). Marx's economic manuscripts of 1861-63 and the 'concept' of dependency. In: Latin American Perspectives, v. 17, n. 2, Post-Marxism, the Left, and Democracy, pp. 62-101.

(2012). A produção teórica de Marx: um comentário ao Grundrisse. São Paulo: Expressão popular.

MARINI, Ruy Mauro. Dialéctica de la Dependência (2008). In: América Latina, dependencia y globalización. Fundamentos conceptuales Ruy Mauro Marini: Antología y presentación Carlos Eduardo Martins. Bogotá: Siglo del Hombre - Clacso. 
(2008). La dialéctica del desarrollo capitalista en Brasil. In: MARTINS, Carlos Eduardo (org.). América Latina, dependencia y globalización. Bogotá: CLACSO y Siglo del Hombre Editores.

(2008). Dialéctica de la dependencia. In: MARTINS, Carlos Eduardo (org.). América Latina, dependencia y globalización. Bogotá: CLACSO y Siglo del Hombre Editores.

(2008). En torno a dialéctica de la dependencia (postscriptum). In: MARTINS, Carlos Eduardo (org.). América Latina, dependencia y globalización. Bogotá: CLACSO y Siglo del Hombre Editores.

(2008). Proceso y tendencias de la globalización capitalista. In: MARTINS, Carlos Eduardo (org.). América Latina, dependencia y globalización. Bogotá: CLACSO y Siglo del Hombre Editores.

(1979). El ciclo del capital en la economia dependiente. In: OSWALD, Ursula (coord.). Mercado y dependencia. México: Nueva Imagen, pp. 37-55. Disponível em: http://www.marini-escritos.unam.mx/008_\%20ciclo_es.htm.

MARX, Karl. (2011). Grundrisse: manuscritos econômicos de 1857-1858: esboços da crítica da economia política. São Paulo: Boitempo; Rio de Janeiro: Ed. UFRJ.

OSORIO, Jaime (2015). America Latina frente al espejo del desarrollo de Corea del Sur y China. In. Revista Problemas del Desarrollo, 182 (46), julio-septiembre.

(2004). Crítica de la economía vulgar: reproducción del capital y dependencia. México: Editorial Miguel Ángel Porrúa, 2004.

ROSDOLSKY, Roman (2001). Gênese e estrutura de O capital de Karl Marx. Rio de Janeiro: EDUERJ: Contraponto.

SANTOS, Theotônio dos (1998). A Teoria da Dependência: Balanços e Perspectivas. Rio de Janeiro: Civilização Brasileira.

\section{Recebido em: 14/04/2017 Aceito em: 13/06/2017}

